\title{
Fault Diagnosis of a Hydraulic Power System Using an Artificial Neural Network
}

\author{
Ahemd El-Betar, Magdy M. Abdelhamed*, Ahmed El-Assal and \\ Roubi Abdelsatar \\ Benha High Institute of Technology, Benha and ${ }^{*}$ Design \&Production \\ Engineering Department, Ain Shams University, Cairo, Egypt

\begin{abstract}
This paper deals with the problem of fault detection, isolation and identification of a hydraulic power system. A proposed fault diagnostic scheme (FDS) using an artificial neural network (ANN) is investigated. A feedforward neural network is employed to diagnose two commonly occurring faults of the hydraulic power system: actuator internal leakage and valve spool blockage. The characterizing model of each fault is derived. The fault diagnostic scheme is applied to a hydraulic power test rig to diagnose real encountered faults. The ANN based FDS has been trained with sufficient data of the faults. Extensive experiments have been carried out and their results are presented and discussed. The experimental results have showed that the trained network has the capability to detect and identify various severity magnitudes of the faults of interest. Furthermore, the trained ANN based FDS has the ability to identify fault levels of untrained fault cases accurately. Therefore, the validity of the proposed FDS as a diagnostic tool for the hydraulic actuator internal leakage and the valve blockage has been assured. Finally, the proposed fault diagnostic scheme can be practically implemented.
\end{abstract} \\ Keywords: Fault diagnostic technique, artificial neural network, \\ hydraulic actuator, oil leakage and valve spool \\ blockage.
}

\section{Introduction}

Over the last two decades, fault diagnosis (FD) has become an issue of primary importance in modern process automation as it provides a basis for the reliable and safe fundamental design features of many complex engineering systems ${ }^{[1]}$. A fault diagnosis is required to avoid power loss in different systems or even loss of human lives. Fault diagnosis aims to 
provide information for time and location of faults that occur in the supervised process. A system is called a healthy system when it runs free of faults, on the contrary, a faulty system is that having deviations from the normal behavior of the system or its instrumentations. Fault diagnosis process includes the following tasks ${ }^{[2]}$ : fault detection, which indicates that something is going wrong in the system, fault isolation which determines the exact location of a fault and fault identification, which determines the magnitude of a fault severity.

Different approaches have been used to diagnose hydraulic system faults. Model-free FD methods utilize multiple sensors to measure the same quantity. Faults are diagnosed by processing the multiple measurements using spectrum analyses or using the logic reasoning approach or comparing the measurement to preset limit values, limit checking approach. On the other hand, model-based FD methods use an explicit mathematical model describing the system, which requires an accurate model for diagnosis ${ }^{[2,3]}$. Another way of FD approaches is to diagnose based on a comparison between real data and mathematical models of the hydraulic system ${ }^{[4]}$. It is a reliable and universal method once the mathematical model is established. However, it is very difficult to establish a reliable mathematical model since the system contains considerable non-linearities and time delays due to frictional forces generated, mechanical looseness and other factors. The other approach is to develop an intelligent system based on expert knowledge and learning of the hydraulic system behaviors.

Current trends in the field of FD of hydraulic systems apply ANNs to diagnose faults of some system components such as valves, actuators, pumps, or sensors. The artificial neural networks (ANNs) have the capability to perform pattern recognition and diagnosis that are difficult to describe in terms of analytical diagnosis algorithms since they can learn input patterns by themselves ${ }^{[5,6]}$. Learning can be viewed as an automatic, incremental synthesis of functional mappings that represent a fault function. Unlike adaptation methods, where the emphasis is on approximating temporal properties, learning systems employ networks with large memory for approximating the spatial dependence of the fault function. Therefore, learning methods can be used not only for fault detection but also for identification of characteristics of the fault through approximation of its functional relation to the measurable state and input variables ${ }^{[7]}$. 
Ramden et al. ${ }^{[8]}$ used ANNs for the FD of a hydraulic control system driven by a planetary gearbox of large vehicle including four directional control valves. The studied faults are the valve stuck in its non-activated and activated positions. Le et al. ${ }^{[9]}$ presented a method using ANNs to detect single and multiple leakage types in a fluid power system including servo valve and a single rod actuator. In Ilott and Griffiths ${ }^{[10]}$, the fault diagnosis of pumping machinery was introduced by applying ANNs concept. They could provide accurate, incipient FD based on real industrial data corresponding to historical pump faults. Crowther et al. ${ }^{[11]}$ presented an ANN approach to the FD of dynamic engineering systems based on the classification of surface in system output vector space. The ANN acted as a parameter estimator and its output was used as fault indicator. Sharif and Grosvenor ${ }^{[12]}$ presented an approach for FD of a control valve unit. The approach is sensor-based in which sensors of pressure, temperature and position were used. The performance of the system was monitored under various conditions to establish the effects of the faults on its operation. In addition, the use of ANNs for sensor validation, data recovery and engine fault diagnosis by using a real engine data is studied in Mesbahi ${ }^{[13]}$. A single feed-forward ANN is trained for engine fault diagnosis purposes and tested against untrained data was achieved. Wang and Jiang ${ }^{[14]}$ presented a method for monitoring and diagnosing the degradation in the performance of valves. A recurrent cerebellar model articulation controller (CMAC) neural network was used to learn the normal characteristics of the valve. Using the trained CMAC neural network, the types and severity of degradation can be identified and estimated. Karpenkoa et al. ${ }^{[15]}$ investigated a neural-network-based scheme for detection and identification of actuator faults in a typical process control valve. Their results showed that the trained network has the capability to detect and identify various magnitudes of the faults of their interest.

In this paper a fault diagnostic scheme (FDS) based on the ANN concept is presented. The internal leakage inside a hydraulic cylinder and control valve spool blockage faults are studied. Testing the proposed FDS on a laboratory hydraulic power system has been carried out. Finally evaluating the performance of the proposed technique has been introduced. The remainder of this paper is organized as follows: In Section 2, the feature and modeling of the interested faults are outlined. Design of the proposed ANN based FDS is introduced in Section 3. Section 4 presents a description of the experimental set up. Section 5 introduces the application of the ANN based FDS on the hydraulic 
power system faults and the experiments carried out in this work. Results and discussions are introduced in Section 6 while conclusions drawn are included in Section 7.

\section{Modeling of the Faults}

The faults of interest are: (i) internal leakage inside the cylinder and (ii) spool blockage of the directional control valve. These faults are probably the most common faults of the hydraulic power system as well as they can not be easily quantified and identified in real time operation of hydraulic systems. This section aims to introduce the mathematical models of the selected faults, the parameters to be monitored to diagnose these faults and how to identify these faults.

\subsection{Mathematical Model of the Oil Leakage Fault}

Figure 1 shows a schematic diagram of a typical hydraulic valveactuator system. The valve orifices are assumed matched and symmetrical. It is also assumed that the line dynamics and losses are negligible, i.e., $P_{l}=P_{s}$ and $P_{2}=P_{e}$, where $P_{1}$ and $P_{2}$ are the pressures at the high-pressure side and the low-pressure side of the actuator respectively, $P_{s}$ and $P_{e}$ are the supply and exit pressures respectively. The following assumptions are considered through this work: the fluid properties are not changed, i.e. the effective bulk modulus $\beta_{e}$ and the density of the fluid $\rho$ are constant, the supply and exit pressures are constant, both valve and actuator parameters are constant and the effect of local variations of working temperature is negligible during the experiments.

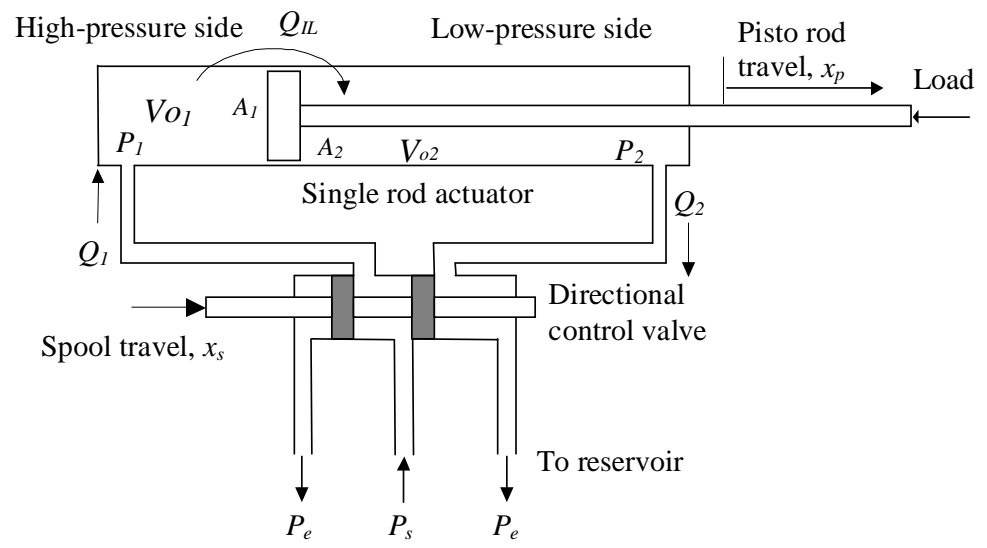

Fig. 1. A schematic diagram of a typical hydraulic valve-actuator system. 
Applying the continuity equation to each of the actuator chamber for extension motion yields ${ }^{[16,17]}$ :

$$
\begin{array}{r}
Q_{1}-Q_{I L}=A_{1} \dot{x}_{p}+\dot{P}_{1}\left(V_{o 1}+A_{1} x_{p}\right) / \beta_{e} \\
Q_{I L}-Q_{2}=-A_{2} \dot{x}_{p}+\dot{P}_{2}\left(V_{o 2}+A_{2} x_{p}\right) / \beta_{e}
\end{array}
$$

The term of internal leakage inside the actuator can be derived from Eq. (1) and (2) as follows:

$$
Q_{I L}=\frac{1}{2}\left[Q_{2}-Q_{1}-\left(A_{1}+A_{2}\right) \dot{x}_{p}-\left(\dot{P}_{1}\left(V_{o 1}+A_{1} x_{p}\right)-\dot{P}_{2}\left(V_{o 2}+A_{2} x_{p}\right)\right) / \beta_{e}\right]
$$

where $Q_{1}, Q_{2}$ are the flow rates at the high-pressure side and the lowpressure side respectively, $Q_{I L}$ is the internal oil leakage flow rate across the actuator piston, $V_{o 1}$ and $V_{o 2}$ are the initial volumes of oil in the actuator sides (Fig. 1), $A_{1}$ and $A_{2}$ are the areas of the piston head from sides 1 and 2 respectively, $x_{p}$ and $\dot{x}_{p}$ are the displacement and the velocity of the piston rod respectively.

Assuming negligible leakage through the cylinder ports, $P_{1}$ and $P_{2}$, relationships for $Q_{1}$ and $Q_{2}$ are written as ${ }^{[16,17]}$,

$$
\begin{aligned}
& Q_{1}=C_{d} A_{p}\left(x_{s}\right) \sqrt{2\left(P_{s}-P_{1}\right) / \rho} \\
& Q_{2}=C_{d} A_{p}\left(x_{s}\right) \sqrt{2\left(P_{2}-P_{e}\right) / \rho}
\end{aligned}
$$

where $C_{d}$ is the valve flow coefficient, $A_{p}\left(x_{s}\right)$ is the valve port area corresponding to the valve spool travel $x_{s}$.

Substituting by $Q_{1}$ and $Q_{2}$ of Eq. (4) and (5) in Eq. (3), the internal oil leakage flow rate across the actuator sides $Q_{I L}$ can be expressed as follows:

$Q_{I L}=\frac{1}{2}\left[\sqrt{\frac{2}{\rho}} C_{d} A_{p}\left(\sqrt{P_{2}-P_{e}}-\sqrt{P_{s}-P_{1}}\right)-\left(A_{1}+A_{2}\right) \dot{x}_{p}-\left(\dot{P}_{1}\left(V_{o 1}+A_{1} x_{p}\right)-\dot{P}_{2}\left(V_{o 2}+A_{2} x_{p}\right)\right) / \beta_{e}\right]$ 


\subsection{Mathematical Model of the Valve Spool-Blockage Fault}

In order to determine the severity of the valve spool-blockage fault, the travel of the spool has to be determined. Considering a rectangular shape of the valve port with a constant width $w$ and substituting by $Q_{1}$ of Eq. (4) in Eq. (1), the travel of the valve spool $x_{s}$ can be expressed as follows:

$$
x_{s}=\left[Q_{I L}+A_{1} \dot{x}_{p}+\dot{P}_{1}\left(V_{o 1}+A_{1} x_{p}\right) / \beta_{e}\right] / C_{d} w \sqrt{2\left(P_{s}-P_{1}\right) / \rho}
$$

From the expression in Eq. (7), it is clear that the valve spool movement $x_{s}$ depends on the variables $P_{1}, \dot{P}_{1}, x_{p}, \dot{x}_{p}$, pressure difference $\left(P_{1}-P_{2}\right)$ valve flow gain and, $Q_{I L}$ which is a function of the parameters $\left(P_{1}, \dot{P}_{1}, P_{2}, \dot{P}_{2}, x_{p}, \dot{x}_{p}\right)$.Other parameters may be considered of constant values. Therefore, the pressure at the high-pressure side $P_{1}$ and its derivative, the pressure at the low-pressure side $P_{2}$ and its derivative, the displacement and the velocity of the piston $\operatorname{rod} x_{p}$ and $\dot{x}_{p}$, are the variable utilized to describe the valve spool jamming fault.

\subsection{Fault Indices}

Fault indices are the parameters that define the fault and its severity. The values of the fault indices will be the outputs of the ANN based FDS of the present work. Dimensionless fault indices that are utilized in this work are described as follows:

For internal oil leakage across the actuator chambers:

$$
a_{1}=Q_{I L} / Q_{1}
$$

For valve spool blockage fault:

$$
a_{2}=x_{s} / s_{s}
$$

where $a_{1}$ and $a_{2}$ are the indices of the internal leakage and valve spool blockage faults respectively, $Q_{I L}$ is the amount of the leakage flow rate between the two chambers of the actuator, $s_{s}$ is the total stroke of the valve spool. 
The values of all fault indices are between zero and one according to the fault severity. For a healthy system, the fault index is zero.

\subsection{Fault Variables and Selecting Minimum Number of Sensors}

It is clear from the mathematical models of the oil leakage and the valve spool-blockage faults, that the variables: $x_{p}, P_{1}$, and $P_{2}$ and their derivatives are sufficient to describe fault indices. Hence, only three sensors are sufficient to diagnose the considered faults. These sensors are two pressure sensors and a velocity sensor.

\section{Design of the ANN-Based Fault Diagnostic System}

The ANN based FDS performs pattern recognition in such that it classifies the input data vectors to different categories according to fault types. This leads to achieve the detection and isolation of the hydraulic power system faults. The ANN based FDS works in two modes sequentially: (i) the training mode and (ii) the fault diagnostic mode.

In the first mode, the ANN learns the performance of either the healthy or faulty hydraulic systems. To work in this mode, sets of the operating data are gathered for the hydraulic power system. Each set of the operating data includes the variables that feature each fault. The outputs of the ANN are the fault indices $a_{1}$ and $a_{2}$, corresponding to each set of the operating data, that represent the type and the magnitude of the fault severity. Healthy and faulty signatures of the hydraulic power system as well as the corresponding fault indices are used to train the ANN to discriminate among the faults of the valve and the actuator. Thus, the first function of the ANN is assigning each operating condition to a specific class of the faults.

In the second mode, the trained ANN works in the diagnostic mode. It receives the hydraulic system signature, i.e., its operating data, and then estimates the fault type and its severity. The trained ANN can directly accomplish the whole task of fault isolation, detection and identification by determining the fault type and its severity. Finally, the trained ANN can execute this task either online, i.e., the hydraulic system is in its operating mode, or offline, i.e., the hydraulic system is in its idle mode. Furthermore, the trained ANN can predict and identify the 
type and severity of untrained fault beside the trained faults based on its level of intelligence.

\subsection{Configuration of the ANN}

Figure 2 shows the architecture of the ANN based fault diagnostic scheme (FDS). The ANN is a multilayer feedforward network (input layer, hidden layer and output layer). There is no inner feedback loop or direct connection from the input layer to the output layer. A hyperbolic tangent activation function is used for each hidden layer neuron while a linear activation function is used for each output layer neuron. The following relation accomplishes the computation of the neural network's outputs $O_{k}(t)$ :

$$
O_{k}(t)=\theta_{k}^{o}(t)+\sum_{j=1}^{N 1} W_{j k}^{h o}(t) \tanh \left(\theta_{j}^{h}(t)+\sum_{i=1}^{N 0} W_{i j}^{i h}(t) I_{i}(t)\right), \quad k=1, N 2
$$

where $N O, N 1$ and $N 2$ are the number of inputs, hidden layer neurons and the output layer neurons respectively, $\theta_{j}^{h}(t)$ are the thresholds of the hidden layer, $W_{i j}^{i h}$ are the weights from the input to the hidden layer and $I_{i}(t), i=1$ to $N O$ are the inputs to the ANN based FDS, $\theta_{k}^{o}(t)$ are the thresholds of the output layer and $W_{j k}^{h o}$ are the weights from the hidden layer to the output layer.

The number of neurons in the hidden layer has to be chosen carefully to ensure that the network was not over-trained thus limiting its generalization ability ${ }^{[19]}$. In this work, the appropriate number of hidden layer neurons is determined experimentally.

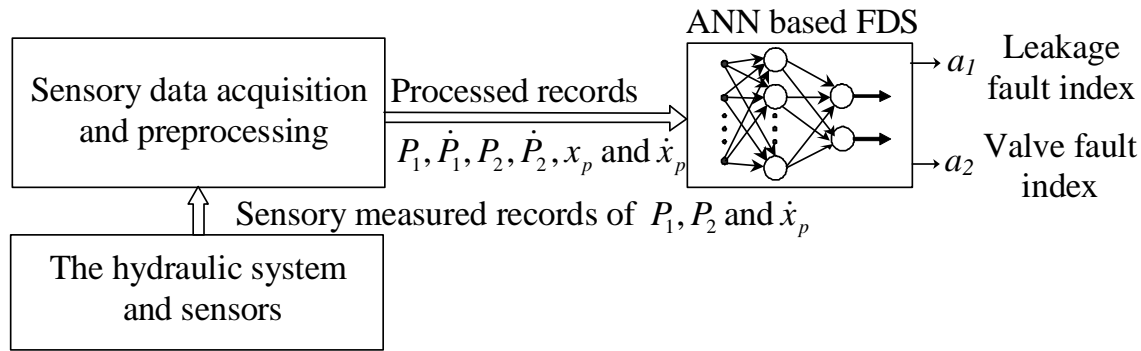

Fig. 2. The architecture of the ANN based fault diagnostic scheme. 


\subsection{Gathering and Preprocessing Data of the ANN-Based Fault Diagnostic System}

Figure 3 shows the architecture of the overall fault diagnostic system based on ANN. The operation of the FDS starts after its training and testing. Measured record readings of the sensors for $P_{1}, P_{2}$, and $\dot{x}_{p}$ that represents the hydraulic system performance, are fed to a data acquisition system. The measured data records are software processed, by differentiating $P_{1}, P_{2}$ and integrating $\dot{x}_{p}$, and rearranged in a matrix form suitable for the ANN. The processed data records are fed to the neural network to accomplish its function either in training or in detection, isolation and identification of the faults.

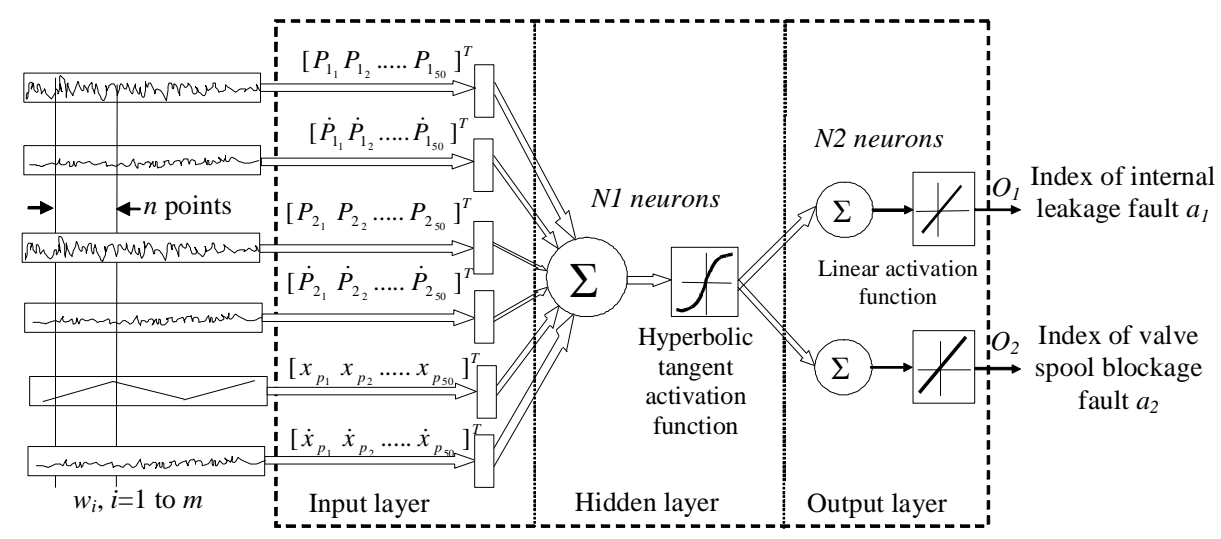

Fig. 3. The architecture of the overall fault diagnostic system using ANN.

\subsection{Training Data}

Referring to Fig. 3, a moving data window, of $n$ points representing the history of each variable, $P_{1}, \dot{P}_{1}, P_{2}, \dot{P}_{2}, x_{p}$ and $\dot{x}_{p}$, is applied to each input of the ANN. Thus, the total inputs to the ANN are $6 n$, i.e., $N 1=6 n$. The outputs of the ANN are 2 which represents the number of fault indices, i.e., $N 2=2$. Both the measured and the processed data representing the input vectors of these three basic variables and the fault indices as output data for all fault cases are fed sequentially to the ANN input layer. Finally, the training input and output data matrices have the following forms, Eq. $(11 \& 12)$ : 


$$
\begin{gathered}
{[I]=\left[\begin{array}{llllllll}
\left\{P_{1}\right\}_{w_{1} c_{1}} & \left\{P_{1}\right\}_{w_{2} c_{1}} & \ldots & \left\{P_{1}\right\}_{w_{m} c_{1}} & \left\{P_{1}\right\}_{w_{1} c_{2}} & \left\{P_{1}\right\}_{w_{2} c_{2}} & \ldots & \left\{P_{1}\right\}_{w_{m} c_{n}} \\
\left\{\dot{P}_{1}\right\}_{w_{1} c_{1}} & \left\{\dot{P}_{1}\right\}_{w_{2} c_{1}} & \ldots & \left\{\dot{P}_{1}\right\}_{w_{m} c_{1}} & \left\{\dot{P}_{1}\right\}_{w_{1} c_{2}} & \left\{\dot{P}_{1}\right\}_{w_{2} c_{2}} & \ldots & \left\{\dot{P}_{1}\right\}_{w_{m} c_{n}} \\
\left\{P_{2}\right\}_{w_{1} c_{1}} & \left\{P_{2}\right\}_{w_{2} c_{1}} & \ldots & \left\{P_{2}\right\}_{w_{m} c_{1}} & \left\{P_{2}\right\}_{w_{1} c_{2}} & \left\{P_{2}\right\}_{w_{2} c_{2}} & \ldots & \left\{P_{2}\right\}_{w_{m} c_{n}} \\
\left\{\dot{P}_{2}\right\}_{w_{1} c_{1}} & \left\{\dot{P}_{2}\right\}_{w_{2} c_{1}} & \ldots & \left\{\dot{P}_{2}\right\}_{w_{m} c_{1}} & \left\{\dot{P}_{2}\right\}_{w_{1} c_{2}} & \left\{\dot{P}_{2}\right\}_{w_{2} c_{2}} & \ldots & \left\{\dot{P}_{2}\right\}_{w_{m} c_{n}} \\
\left\{x_{p}\right\}_{w_{1} c_{1}} & \left\{x_{p}\right\}_{w_{2} c_{1}} & \ldots & \left\{x_{p}\right\}_{w_{m} c_{1}} & \left\{x_{p}\right\}_{w_{1} c_{2}} & \left\{x_{p}\right\}_{w_{2} c_{2}} & \ldots & \left\{x_{p}\right\}_{w_{m} c_{n}} \\
\left\{\dot{x}_{p}\right\}_{w_{1} c_{1}} & \left\{\dot{x}_{p}\right\}_{w_{2} c_{1}} & \ldots & \left\{\dot{x}_{p}\right\}_{w_{m} c_{1}} & \left\{\dot{x}_{p}\right\}_{w_{l} c_{2}} & \left\{\dot{x}_{p}\right\}_{w_{2} c_{2}} & \ldots & \left\{\dot{x}_{p}\right\}_{w_{m} c_{n}}
\end{array}\right]} \\
{[O]=\left[\begin{array}{lllllll}
a_{1 w_{1} c_{1}} & a_{1 w_{2} c_{1}} & \ldots & a_{1 w_{m} c_{1}} & a_{1 w_{1} c_{2}} & a_{1 w_{2} c_{2}} \ldots & a_{1 w_{m} c_{n}} \\
a_{2 w_{1} c_{1}} & a_{2 w_{2} c_{1}} & \ldots & a_{2 w_{m} c_{1}} & a_{2 w_{1} c_{2}} & a_{2 w_{2} c_{2}} \ldots a_{2 w_{m} c_{n}}
\end{array}\right]}
\end{gathered}
$$

where $I$ and $O$ are the input and output matrices respectively. $w_{i},(i=1$ to $m$ ) is the $i^{\text {th }}$ data window, which covers 50 points length, $m$ is the total number of windows covering the extending stroke of the actuator rod. $c_{j}$, $(j=1$ to $n)$ is the $j^{\text {th }}$ fault case while $n$ is the total number of healthy and faulty cases.

\subsection{Training Process of the ANN-Based Fault Diagnostic System}

Several learning algorithms have been proposed to adjust the weight values of the ANN based FDS. The backpropagation (BP) method is widely used as a learning method for an ANN especially for offline learning. The main advantage of the BP method is that the teaching performance is highly improved by the introduction of a hidden layer ${ }^{[5,6]}$. In this paper, BP learning rules with momentum and adaptive learning rate are used to adjust the weights and biases of networks through minimizing the sum squared error of the ANN. This is done by continually changing the value of the ANN weights and biases in the direction of steepest descent with respect to the error. The BP with momentum method decreases BP's sensitivity to small details in the error surface. This helps the training process to avoid being stuck in shallow minima. In addition, training time can also be decreased by the use of an adaptive learning rate, which attempts to keep the learning rate step size as large as possible while keeping learning stable. These two techniques can be used with BP to make it a faster, more powerful, and more useful learning paradigm ${ }^{[5]}$. The training process starts with initial random value of the weights $W_{i j}^{i h}, W_{j k}^{h o}$ and the biases $\theta_{j}^{h}$ as well as $\theta_{k}^{o}$. 


\section{Experimental Setup Description}

\subsection{The Test Rig Description}

Figure 4 shows a schematic layout of the test rig while Fig. 5 shows a photo of the experimental setup. The test rig used in this work consists mainly of three items, the hydraulic system, the control unit, and the data acquisition system. Figure 6 depicts a schematic layout of the tested hydraulic system. As shown in this figure, the cylinder 1 is the test cylinder, which is driven by $4 / 3$ directional control valve (DCV) with double solenoids and double springs for centering position (Type Dynex/Rivett 6550-D03-24VDC-10). Cylinder 2 works as a load unit, which is driven by a bridge equalizer to control the velocity of both cylinders and apply a load. Each actuator cylinder has a bore diameter of $50 \mathrm{~mm}$, a rod diameter of $25 \mathrm{~mm}$ and a stroke of $300 \mathrm{~mm}$. There are two similar hydraulic power units utilized to drive each actuator separately. Each hydraulic power unit can supply a flow rate of $9.46 \mathrm{l} / \mathrm{min}$ while the maximum pressure of each unit is adjusted at 34.5 bar. An accumulator is connected to the input side of the directional control valve to minimize local fluctuations of the input supply pressure. The motion of the hydraulic cylinders is controlled through a relay control circuit. The sensor measurements are fed to a $\mathrm{P} 4-1.8 \mathrm{GHz}$ personnel computer (PC) through an interfacing data acquisition system (a portable data collector). This portable data collector, supplied by Hydac (Type is HMG2020), acquires the sensory signals of the pressures $P_{1}$ and $P_{2}$ and the displacement $x_{p}$ sensors. It can receive five different sensor signals simultaneously, perform preprocessing and data conditioning, and then sends output signals to the PC. Two identical pressure transducers (Type HDA3744) and a linear encoder, made by Acurite (Type ENC-150) are utilized to give the operating data of the tested hydraulic system.

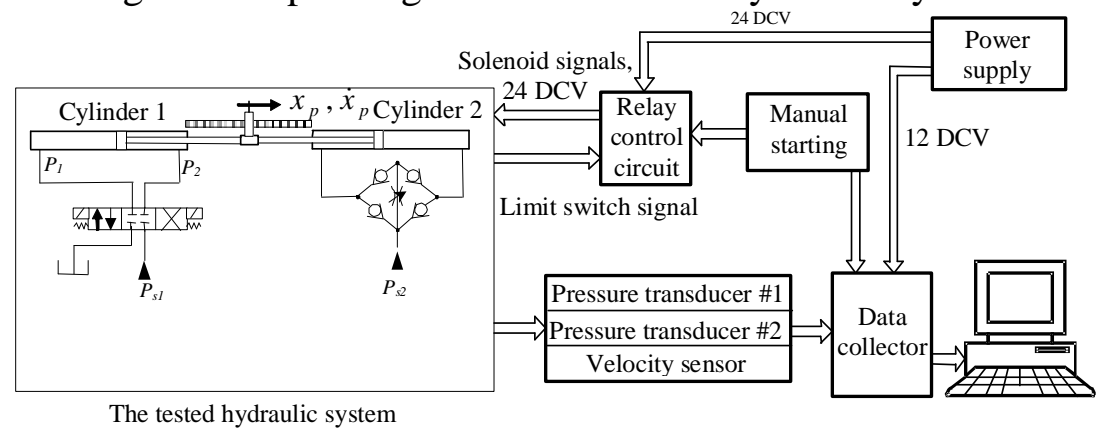

Fig. 4. A schematic layout of the test rig. 


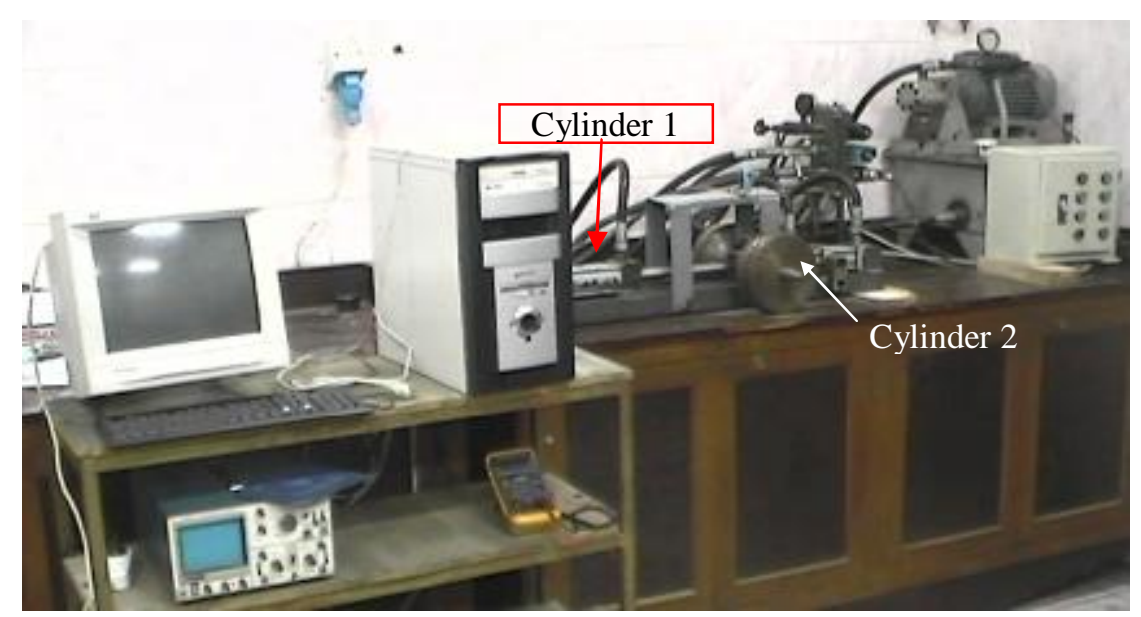

Fig. 5. A photograph of the experimental setup.

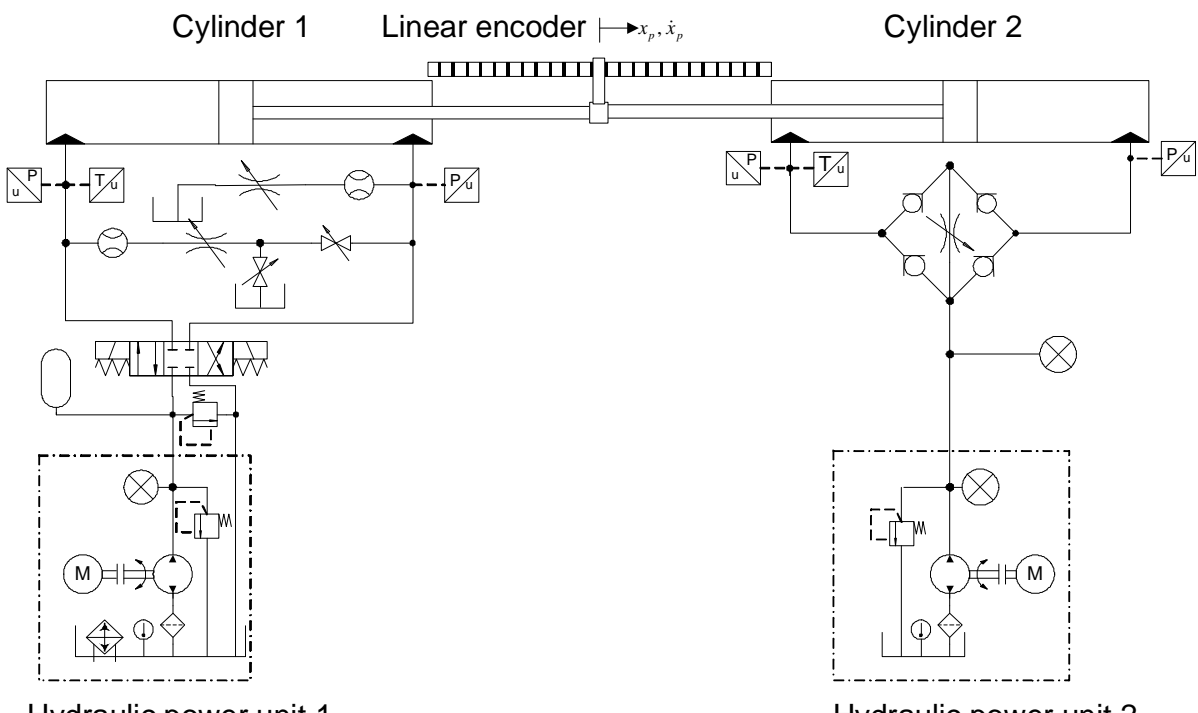

Hydraulic power unit 1

Hydraulic power unit 2

Fig. 6. A schematic layout of the tested hydraulic system.

\subsection{Experimental Implementation of the Faults}

Oil Leakage Fault: Keeping a measured flow rate $Q_{I L}$ of oil passing between both sides of cylinder 1 through an external bypassing line simulates the internal leakage. The bypass line has a needle valve to control the leaked flow rate grade and a flow meter to measure the 
quantity of leaked flow rate. Thus, the fault index $a_{1}$ can be determined as given in Eq. (8).

Valve Fault: A mechanism is prepared to control the movement of the valve spool where a setscrew can be adjusted to control the position of the spool. This leads to control the port area of the DCV. Measuring the travel of this setscrew and the stroke of the valve spool, the valve fault index $a_{2}$ can be determined as given in Eq. (9).

\section{Experimental Runs Carried out on the ANN Based FDS as Applied on the Present Hydraulic Test Rig}

Extensive sets of experiments have been carried out on the hardware setup of the hydraulic system. The aim of the experiments is to gather data to train, test and evaluate the ANN based FDS. The carried on experiments can be classified into two categories. The first category represents all experiments used to train the ANN while the second category represents the experiments used to test and evaluate the ANN based FDS. These experiments are:

i. Experiments of a healthy system (Four experiments $\mathrm{H}_{1}$ to $\mathrm{H}_{4}$ ).

ii. Experiments of an internal leakage fault (Four experiments $\mathrm{IF}_{1}$ to $\mathrm{IF}_{4}$ ).

iii. Experiments of a valve spool blockage fault (Four experiments $\mathrm{VF}_{1}$ to $\left.\mathrm{VF}_{4}\right)$.

All these experiments have been carried out at $100 \mathrm{~Hz}$ sampling rate. Collecting the data of these experiments is accomplished at the steady state condition. The range of the temperature $T_{1}$ is between $36{ }^{\circ} \mathrm{C}$ to $40^{\circ} \mathrm{C}$, the ranges of $P_{1}$ and $P_{2}$ are from $31.1 \mathrm{bar}$ to $31.7 \mathrm{bar}$ and from 1 to 1.2 bar respectively and the range of the velocity $\dot{x}_{p}$ is between $29.2 \mathrm{~mm} / \mathrm{s}$ and $30.4 \mathrm{~mm} / \mathrm{s}$. Eighteen measuring records were captured over a complete stroke of the hydraulic cylinder. The length of each record contains six data windows, i.e., one window per each variable of $P_{1}, P_{2}, x_{p}$ and their derivatives. The number of data per a record is 300 points. Table 1 outlines the experiments, their classification as well as their conditions. 
Table 1. Experiments: Classification and conditions.

\begin{tabular}{|c|c|c|c|c|}
\hline \multicolumn{3}{|c|}{ Experiment condition and its classification } & \multicolumn{2}{|c|}{ Fault indices } \\
\hline Usage & Classification & Code & $a_{1}$ & $a_{2}$ \\
\hline \multirow{9}{*}{$\begin{array}{l}\text { For training } \\
\text { the ANN } \\
\text { based FDS }\end{array}$} & \multirow[b]{3}{*}{ Healthy } & $\mathrm{H}_{1}$ & 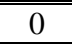 & 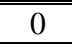 \\
\hline & & $\mathrm{H}_{2}$ & 0 & 0 \\
\hline & & $\mathrm{H}_{3}$ & 0 & 0 \\
\hline & \multirow[b]{3}{*}{ Internal leakage fault } & $\mathrm{IF}_{1}$ & 0.14 & 0 \\
\hline & & $\mathrm{IF}_{2}$ & 0.36 & 0 \\
\hline & & $\mathrm{IF}_{3}$ & 0.42 & 0 \\
\hline & \multirow[b]{3}{*}{ Valve spool blockage fault } & $\mathrm{VF}_{1}$ & 0 & 0.5 \\
\hline & & $\mathrm{VF}_{2}$ & 0 & 0.63 \\
\hline & & $\mathrm{VF}_{3}$ & 0 & 0.75 \\
\hline \multirow{3}{*}{$\begin{array}{c}\text { For testing } \\
\text { the ANN } \\
\text { based FDS }\end{array}$} & Healthy & $\overline{\mathrm{H}} \mathrm{H}_{4}$ & 0 & 0 \\
\hline & Internal leakage fault & $\mathrm{IF}_{4}$ & 0.44 & 0 \\
\hline & Valve spool blockage fault & $\mathrm{VF}_{4}$ & 0 & 0.25 \\
\hline
\end{tabular}

\section{Results and Discussion}

\subsection{Effect of the Measured Variables on the Fault Indices}

Figures 7(a) and 7(b) depict the effect of the internal leakage and valve spool blockage indices $a_{1}$ and $a_{2}$ respectively on the measured variables $P_{1}, P_{2}$ and $\dot{x}_{p}$. The figures reveal that:

- The pressure $P_{1}$ is inversely proportional to the severity of the valve spool blockage and the internal leakage faults. This coincides with the simulation results introduced in Ref. [18].

- The pressure $P_{2}$ increases with the severity of the internal oil leakage, which is also compatible with the mathematical model simulation presented in Ref. [18].

- The velocity of the actuator piston rod, $\dot{x}_{p}$ has the same behavior of the pressure $P_{1}$ to the severity of the internal leakage and spool blockage faults. 


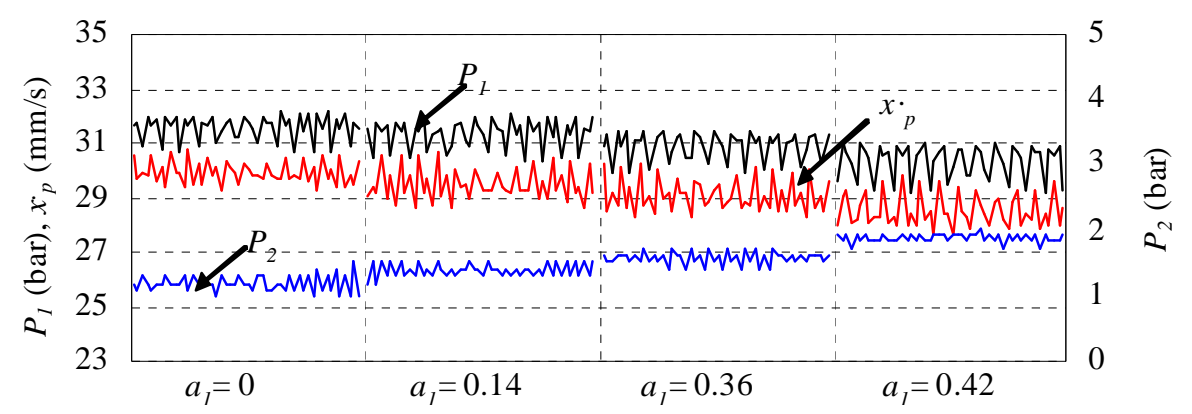

(a)

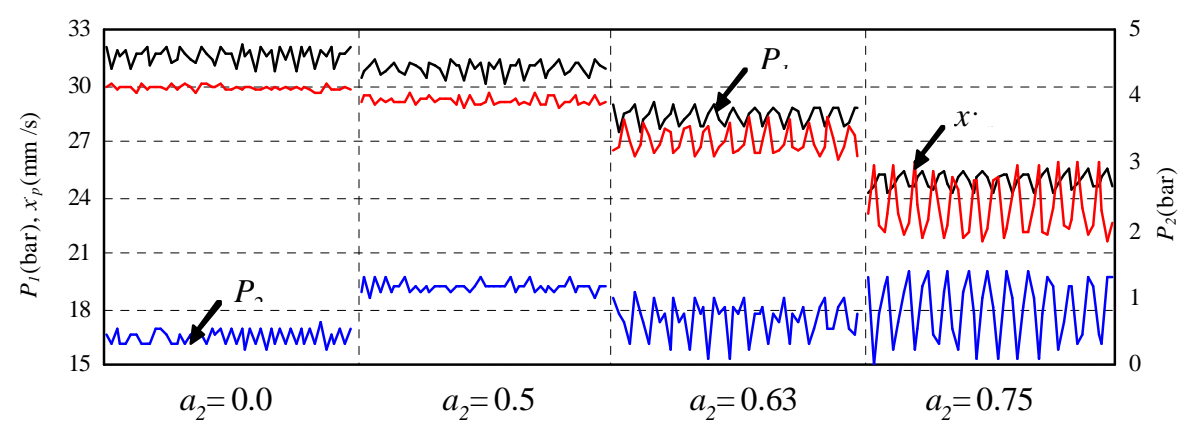

(b)

Fig. 7: (a) Effect of the internal leakage severity, represented by $a_{1}$ value, on $P_{1}, P_{2}$ and $\dot{x}_{p}$,

(b) Effect of the valve spool blockage severity represented by $a_{2}$ value on $P_{l}, P_{2}$ and $\dot{x}_{p}$.

\subsection{Training the ANN}

Extracting the training data for the ANN: To decide the training data of the ANN according to Eq. (10) to (12), nine healthy and faulty cases are used for training the ANN as outlined in Table 1. Each case covers eighteen windows of the piston extending stroke; $l=18$ of $0.5 \mathrm{sec}$ per window. This means that the number of columns of the input matrix $I$ is 162 while the number of rows of this matrix is 150 , i.e., the dimension of $I$ is $150 \times 162$. For the output matrix, there are two-fault indices $a_{1}$ and $a_{2}$. According to the number of cases studied and the number of windows covered the extending stroke of the piston rod, the number of column is the same as the input matrix. This means that the dimension of the $O$ matrix is $2 \times 162$.

Both the input and output training data were gathered by implementing the different cases outlined in Table 1 and prepared in the form of $I$ and $O$ matrices. Figure 7 shows the average of the input 
training data of the different healthy and faulty cases. Noting that each point of each $P_{1}, P_{2}$ and $\dot{x}_{p}$ represents the average of 900 points which are actually used in training the ANN.

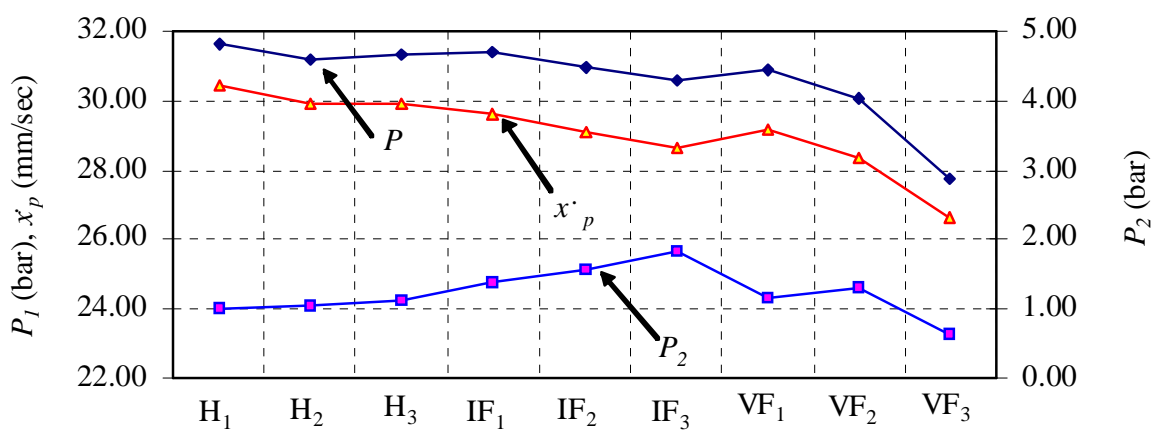

Fig. 8. Average values of $P_{1}, P_{2}$ and $\dot{x}_{p}$ of the cases used in learning the ANN.

Selecting the Number of Nodes in the Hidden Layer (N1): The problem of the size choice of the hidden layer is under intensive study without conclusive answers ${ }^{[5,6]}$. The exact analysis of the issue is rather difficult because of the complexity of the network mapping ${ }^{[6]}$. The learning performance of ANN based FDS has been extensively tested under the effect of different numbers of nodes in the hidden layer to attain a mean square error $=0.005$. Some of these results are outlined in Table 2 . Based on this study, the number of 30 nodes in the hidden layer yields good training results. Therefore the ANN based FDS size is 150:30:2.

Table 2. Effect of hidden layer node number on the learning.

\begin{tabular}{|l|l|}
\hline N1 & Epochs No. for training convergence \\
\hline 5 & Not converged \\
\hline 10 & 377282 \\
\hline 20 & 7890 \\
\hline 30 & 5447 \\
\hline 50 & 5502 \\
\hline
\end{tabular}

Learning of the ANN-Based Fault Diagnostic Scheme: The training procedure establishes the mapping between the cases of operating conditions of the hydraulic power system, $P_{1}, P_{2}, \dot{x}_{p}$ and the corresponding values of the fault severities or fault indices $a_{1}$ and $a_{2}$. The BP training algorithm with momentum and an adaptive learning rate is applied to determine both the 
weights and the biases of the ANN. A sum squared network training-stopping criterion is selected to be 0.001 . The weights, the biases and other parameters of the trained ANN-based FDS are determined.

\subsection{Testing and Evaluating the Trained ANN Based FDS}

Two sets of data have been used for testing the performance of the trained ANN. The first set is the trained cases, $\mathrm{H}_{1}$ to $\mathrm{H}_{3}, \mathrm{IF}_{1}$ to $\mathrm{IF}_{3}$ and $\mathrm{VF}_{1}$ to $\mathrm{VF}_{3}$, while the second set is the untrained cases, $\mathrm{H}_{4}, \mathrm{IF}_{4}$ and $\mathrm{VF}_{4}$ as given in Table 1. Figures 9(a) and 9(b) show the performance of the trained ANN for the internal leakage and the valve spool blockage faults respectively. These figures reveal the following:

- The outputs of the trained ANN are noticed to track the variation in the leakage fault index quite well. Thus, the ANN based FDS is capable to detect the internal leakage inside the cylinder.

- The ANN has successfully learned the valve spool blockage fault since the outputs of the valve fault index neuron varies in accordance with the status of the valve blockage fault index targets.

- The ANN is able to identify a fault severity not present in the training data.

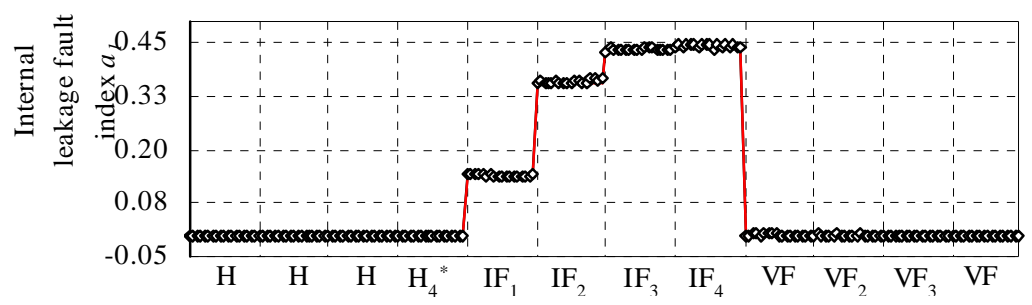

(a) Performance of the trained ANN for the internal leakage fault

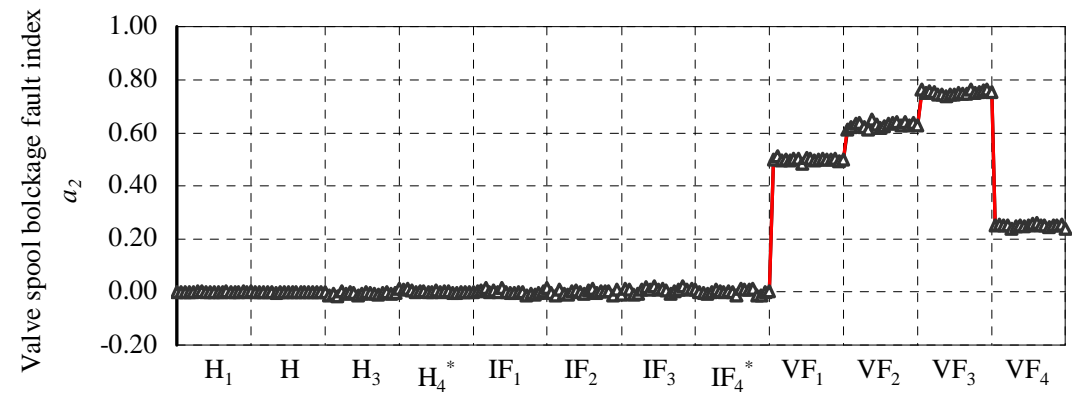

(b) Performance of the trained ANN for the valve spool blockage fault

Fig. 9. Performance of the trained ANN based FDS to the interesting faults: The symbol “*”" indicates the untrained cases that are used only for testing and evaluating the ANN. 


\section{Conclusions}

This paper has outlined a proposed fault diagnostic scheme of a hydraulic power system. The FDS is based on the neural networks. The actuator internal leakage and valve blockage that are amongst the common problems associated with the abnormal operation of the power hydraulic system are considered and studied. The designed ANN based FDS has been trained with sufficient experimental data as applied to a hydraulic power test rig. Real time experiments have been carried out to test the validity and the effectiveness of the proposed diagnostic system. From the results of these experiments, the following conclusions are drawn:

1. Three sensors are found to be sufficient to diagnose the faults of the valve and actuator. These sensors are two pressure sensors and one velocity sensor. The values of the operating variables of these sensors as well as the corresponding fault indices develop a significant fault signature for each fault.

2. The trained ANN based FDS has the capability to isolate, detect and identify the various severity magnitudes of the faults of interest.

3. The trained ANN is able to identify accurately a fault severity not present in the training data.

4. The proposed FDS can be practically implemented and thus it is useful for maintenance and process engineers.

5. Future work in this branch includes investigating more faults like sensor faults, internal scratches of the actuator, seal failure, bending the piston rod, piston head looseness and other fault combinations.

\section{References}

[1] Hammouri, H., Kabore, P., Othman, S. and Biston, J., "Failure diagnosis and nonlinear observer application to a hydraulic process", Journal of the Franklin Institute, 339: 455-478 (2002).

[2] Gertler, J. J., "Fault Detection and Diagnosis in Engineering Systems," Marced Deker Publisher (1998).

[3] Nyberg, M. and Stutte, T., "Model based diagnosis of the air path of an automotive diesel engine", Control Engineering Practice, 12( 5) May : 513-525 (2004).

[4] Rashidy, H., Saafan,A., Rezeka, S. and Awad, T., "Fault diagnosis of a hydraulic servo valve using a neuro-fuzzy model" , Proc. of ESDA2002, $6^{\text {th }}$ Biennial Conf. on Engineering systems Dynamic and Analysis, Istanbul, Turkey, July 8-11, pp:1-8 (2002). 
[5] Abdelhameed, M.M. and Tolbah, F. A., "Design and implementation of a flexible manufacturing system using neural network," International Journal of Flexible Manufacturing Systems, 14 (3) July : 263-280 (2002)..

[6] Abdelhameed, M.M. and Tolbah, F. A., "A recurrent neural network based sequential controller for manufacturing automated systems" , Int. Journal of Mechatronics, 12:617633 (2002).

[7] Polycarpou, M. M. and Tunov, A. B., "Learning approach to nonlinear fault diagnosis delectability conditions and detection time in a nonlinear fault diagnosis scheme based on the learning approach", IEEE Tran. on Automatic Control, 45 (4) April : 806-812 (2000).

[8] Ramden, T., Krus, P. and Plamberg, J., "Fault diagnosis of complex fluid power systems using neural networks," The Fourth Scandinavian International Conference on Fluid Power, Tampere, Finland (1995).

[9] Le, T., Watton, J. and Pham, D. T., "An artificial neural network based approach to fault diagnosis and classification of fluid power systems", Proc. Instn Mech. Engrs, 211(Part I) IMechE: 307-317 (1997)

[10] Ilott, P. W. and Griffiths, A. J., "Fault diagnosis of pumping machinery using artificial neural networks", Proc. Instn Mech. Engrs, 211(Part E) IMechE: 185-194 (1997).

[11] Crowther, W. J., Edge, K. A., Burrows, C. R., Athinson. R. M. and Woollons, D. J., "Fault diagnosis of a hydraulic actuator circuit using neural networks-an output vector space classification approach" , Proc. Instn Mech. Engrs, 212(Part I) 1MechE: 57- 68 (1998).

[12] Sharif, M. A. and Grosvenor, R. I., "Sensor-Based Performance Monitoring of a Control Valve Unit", IMech, 213 (1): 71-84 (1999).

[13] Mesbahi, E., "An intelligent sensor validation and fault diagnostic technique for diesel engines" , Journal of Dynamic Systems, Measurement, and Control, 123 (1) March: 141144 (2001).

[14] Wang, S. and Jiang, Z. "Valve fault detection and diagnosis based on CMAC neural networks", Energy and Buildings, 36(6) June: 599-610 (2004).

[15] Karpenkoa, M., Sepehria, N. and Scuse, D., "Diagnosis of process valve actuator faults using a multilayer neural network", Control Engineering Practice, 11: 1289-1299 (2003).

[16] Merritt, H. E., “Hydraulic Control System”, John Wiley and Sons, New York (1967).

[17] Cetinkunt, S., Pinsopon, U., Chen, C., Egelja, A. and Anwar, S., "Positive flow control of closed-center electrohydraulic implement-by-wire systems for mobile equipment applications", Mechatronics, 14: 403-420 (2004).

[18] Roubi Abdelstar, "A fault diagnosis system using neural networks," M.Sc. Thesis, Benha High Institute of Technology, Egypt, Benha (2003).

[19] Power, Y. and Bahri, P.A., "A two-step supervisory fault diagnosis framework," Computers and Chemical Engineering, Article in press, Available online at www.sciencedirect.com (2004). 


\title{
تشخيص الأعطال في منظومة قدرة هيدروليكية باستخدام الثبكات العصبية الاصطناعية
}

\author{
أحمد البيطار، ومجدي عبد الحميد*، وأحمد العسال،

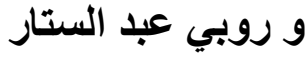 \\ قسم الهندسة الميكانيكية ــ الدعه العالي للتكنولوجيا ببنها، * قسم التصديم \\ والإنتاج - كلية الهندسة ـ جامعة عين شمس - القاهرة - مصر \\ المستخلص ، تم التعامل مع مشكلةِ كثنفِ العطلِ وعزللهِ وتعريفهِ \\ في منظومة قدرة هيدروليكيةِ، و النظام المقترح في هذا لبند البحث

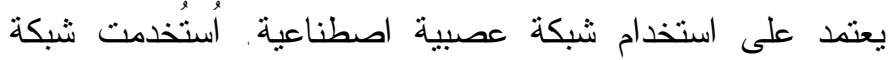

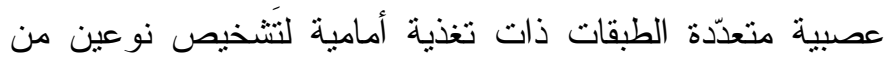 \\ الأعطال الثائعة الحدوث في منظومات القدرة الهيدروليكية، وهما: \\ تسرب الزيت داخليا عبر مكبس أسطوانة المشغّل وإعاقة بكرة \\ صمام التحكم التوجيهي، و التي تسبب الإغلاق الجزئي للصمام.

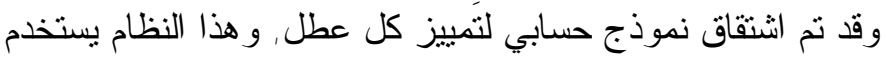 \\ الحد الأدنى من أجهزة القياس اعتمادا على فصل المتغيرات

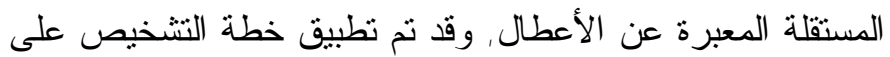

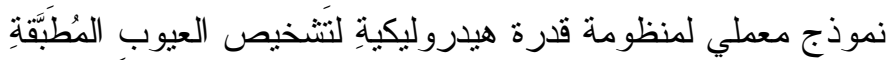 \\ الحقيقيةً, وقد نم تدريب منظومة التشخيص المعتمدة على الثبكة \\ العصبية باستخدام بيانات كافية للأعطال . \\ نم تتفيذ التجارب الثشاملة، وعرض ومناقثة نَتائجَها. وقد أظهرت

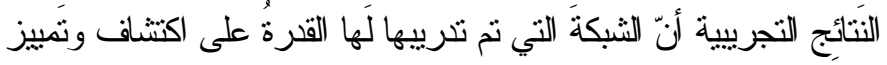

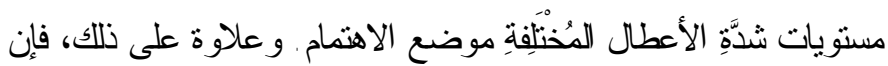

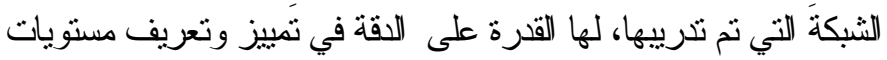

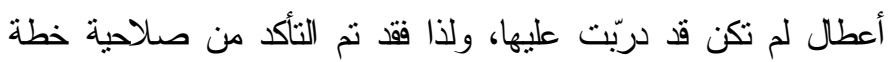


137 Fault Diagnosis of A Hydraulic Power System Using an Artificial Neural Network

التشخيص المقترحة كأداة نتخيصية لتسرب الزيت داخليا عبر مكبس

أسطو انة الشغّل و إعاقة بكرة صمام للتحكم التوجيهي. كما أظهر نظام

النشخيص المقتزح في هذا البحث أداءً جيدا، مما يجعله قابلا

للتَطبيق عمليُا. 